\title{
HANNAH SIMPSON
}

\section{Samuel Beckett and Disability Performance}

Harold Pinter's performance as Krapp in Ian Rickson's 2006 Royal Court production of Krapp's Last Tape was acclaimed as 'a triumphant final hurrah for Mr Pinter' (Cowell, 2006). Seventy-six years old at the time, Pinter had recently survived oesophageal cancer and pemphigus vulgaris and, as a result of his poor health, used an electric wheelchair during the performance. Although not included in the original script, the wheelchair offered a fitting complement to Beckett's exploration of physical decline, as several reviewers remarked. Susannah Clapp noted that 'the electric wheelchair that whizzes round the stage truly looks like a Beckett prop' (Clapp, 2006), and The Times critic Benedict Nightingale observed that although 'Pinter's Krapp glides about on an electric wheelchair [...] instead of tottering in and out of the drab old room', still 'this is surely a performance that would have delighted Beckett' (Nightingale, 2006).

There are very few wheelchairs in Beckett's stage plays. The only specified instance appears in the little-performed Rough for Theatre I, and even Hamm in Endgame is left longing for 'a proper wheelchair. With big wheels' in place of his armchair on castors (Beckett, 2006, 104). Yet Beckett's plays have attracted a striking range of disability performances, in part because of their insistent attention on embodied existence and the impaired body. The term 'disability performance' here describes a production in which one or more disabled actors perform the play on stage, regardless of whether or not their roles are explicitly described as disabled in the text. This article examines four recent disability performances of Beckett's plays: Robert Rae's 2007 Endgame at Theatre Workshop Scotland in which Nabil Shaban and Garry Robson, both wheelchair users, played Hamm and Clov; The Endgame Project, in which Dan Moran and Chris Jones, who each have Parkinson's disease, played Hamm and Clov at Classic Stage Company in 2012; the 2018 Touretteshero production of Not I at Battersea Arts Centre, in which Jess Thom, who has Tourette's syndrome, played Mouth; and Culture Device's 2018 production of Waiting for Godot at Hackney Showroom, performed by a cast of professional actors with Down syndrome. Drawing on a series of original interviews with the practitioners involved in these performances, ${ }^{1}$ this article focuses on how these productions prompt re-evaluation of the previously undetected indicators of disability (or of embodied 
experiences that resonate with particular disabilities) in Beckett's scripts, such as mobility impairment, automatic speech, stuttering, and memory deficiency. This in turn provokes the associated question of the intersection between ethics and aesthetics in these performances: that is, the relative accord or discord between textual aesthetics and disability ethics. Previous analysis of disability performances of Beckett work reveals the recurrent suspicion that 'sociopolitical engagement' and 'the aesthetic and artistic values of Beckett's texts' are somehow mutually exclusive (Horvat, 2016, 172). When they lack Pinter's crowd-drawing 'star power', disability performances are often critiqued - or disallowed entirely - because of an anxiety that the access measures which enable performance come at the expense of textual integrity, or that the disabled body onstage will introduce a new dimension to the performance that distracts from the 'real' concerns of Beckett's plays. By contrast, this article explores how we might understand these productions to be highlighting, in newly embodied terms, elements which have always been central to the original playtexts, without attempting to make Beckett's playtexts about specific disabilities in any oversimplified sense.

\section{Endgame, dir. Robert Rae, Theatre Workshop Scotland, 2007}

In November 2007, Robert Rae directed Endgame, a co-production between Sharmanka Theatre Glasgow and Theatre Workshop Scotland, the latter a theatre company with a long history of disability performance and inclusive casting. The production featured two wheelchair users: Nabil Shaban, an actor with restricted growth as a result of osteogenesis imperfecta, and Garry Robson, who has mobility issues following childhood polio. In Rae's production, Shaban's Hamm was perched in a large gilded cage that hung from the ceiling above the stage, while Robson's Clov moved about the stage below, in a wheelchair equipped with prosthetic legs that he could 'stamp' to fool Hamm into believing he was walking. These alterations in Endgame's stage directions were widely criticised as a recusant revision of Beckett's script. The Telegraph's theatre critic Mark Brown, for example, highlighted the casting of wheelchair-user Robson as Clov, whose 'debility is that he is unable to sit', as 'a particularly radical departure' from Beckett's original text, and argued that Clov's fooling Hamm with his wheelchair's prosthetic legs profoundly reshaped the relationship between the two protagonists: 'The balance of power between the two men is altered almost beyond recognition, shifting away from Hamm towards Clov' (Brown, 2007). Similarly, Kirsty 
Johnston cites the artistic evaluation of Sita Ramamurthy, one of the specialist advisors from the Scottish Arts Council funding body, who argued that director Rae 'tried too hard to convey his interpretation of the text as opposed to allowing the text to be revealed'. Rae argued in response, 'Apart from the adaptations required because of impairments of the actors, I was faithful to Beckett's own directions' (qtd. in Johnston 2016, 105). Rae's retort is somewhat disingenuous - the set's suspended gilded cage, for example, seems unrooted in any impairment-related access measure - but we might nevertheless find such criticism curious levelled at a script so populated with disabled characters. This is a play in which the four lead characters each exhibit distinct mobility impairments: Hamm who cannot stand up, Clov who walks with a pronounced limp, and Nagg and Nell who have 'lost their shanks'. As Johnston queries, 'How was this famous play that turns on disabled figures challenged by casting disabled actors?' $(2016,104)$.

One answer might lie in the fact that, as Ato Quayson notes, physical disabilities in Endgame have often been displaced from critical attention, interpreted more as 'ciphers of the frailty of the human condition and not to be read as markers of any real disability as such' (2007, 83). Disabled individuals and disability theorists have resisted such 'symbolic' scriptings, pointing out that the lived reality of disability should not be reduced to a metaphorical expression of the able-bodied imagination, 'as a metaphor for evil, or for bravely struggling against the odds', as Robson puts it (2017), and much modern literary scholarship has challenged such reductive interpretative strategies. ${ }^{2}$ Robson and Shaban, however, explain that their performances were influenced by their sense that Beckett's play is not 'about disability' in any material sense, but in fact does use impairments more associatively or allegorically. Shaban argues, 'I don't really think Endgame is necessarily about disability [...] or about a disabled person as such' (2017). The play, he suggests, uses 'the short-hand of impaired bodies or senses to evoke feelings of anguish and anomie in the audience':

I think Beckett was using impairments as metaphors for something else: for alienation or anger or despair or hopelessness or powerlessness. And in a way that's kind of a typical a non-disabled person's attitude towards disabled people. [...] He was providing ideas or experience of human existence, and using impairment or limitations of human sensories or mobilities as expressions of his frustration and his fears. (Shaban, 2017) 
Shaban's observation here echoes Quayson's argument that Endgame refuses to offer any stable grounding for either an allegorical or any materially or socially realistic representation of disability. It becomes instead a 'hermeneutical conundrum' in Beckett's writing, denied any stable ontological status within the text (2007, 84-5).

However, in contrast to Shaban's spirited championing of the legitimate joys and attractions of the disabled body, Quayson's theorising is problematically grounded in his suggestion that the encounter with an impaired body necessarily elicits anxiety as a result of how it disturbs normative ideals of the able-bodied. 'Ultimately, aesthetic nervousness has to be seen as co-extensive with the nervousness regarding the disabled in the real world', Quayson claims, alleging that the disabled body invariably generates a 'subliminal fear and moral panic' in the viewing subject, by disrupting symbolic notions of 'wholeness' and 'beauty' and recalling to its viewer 'the provisional and temporary nature of able-bodiedness' $(2007,19$, 14-15). The resultant intense emotional discomfort is the only possible response that Quayson allows in the encounter with the disabled body - there is no space for acceptance, celebration, admiration, erotic interest, or even indifference - and he declares that this framework of anxious response holds regardless of whether the observing subject has a lived experience of disability or not $(16,18)$. To accept Quayson's theory of how 'aesthetic nervousness' functions in Beckett's writing, we are also asked to accept the dark idea of the disabled body's invariably discomforting presence on which Quayson grounds his claims.

Of course, this acceptance is not always readily forthcoming. When I ask Shaban to respond to a brief excerpt of Quayson's theory that the 'subliminal fear and moral panic' provoked in the spectator is central to Endgame's emotional functioning, he gives a pained sigh, and says, 'Well, I'm a disabled person, so I'm unlikely to experience aesthetic nervousness on seeing another person onstage. So I wouldn't know what on earth they're talking about' (Shaban, 2017). Shaban's exasperated response underscores the difficulty - even the moral distastefulness - in attempting to align Quayson's theory of the claimed 'nervous' response to the impaired body with a disabled individual's concept of their own existence, and gives the lie to Quayson's idea of a monolithically resistant response to the disabled body. However, Shaban does not deny the possibility that Beckett's play does use the impaired body as a means of deliberately generating an intense affective form of 'nervous' response - if not quite one so grounded in a seemingly immutable ableist response to the disabled individual as Quayson suggests. Endgame's representation of bodily disability in the play is not affectively neutral. Hamm begs in vain for pity, painkiller, and death (Beckett, 2006, 96, 127, 130), and urinates in his chair (108), while dreaming of regaining his sight and mobility: 'I'd go into the 
woods. My eyes would see... the sky, the earth. I'd run, run' (100). Endgame plays on the manner in which the physically disabled body, 'constructed as the embodiment of corporeal insufficiency and deviance', becomes a repository for social anxieties about vulnerability and decline (Garland-Thompson, 1997, 6). Physical impairment is used to heighten the affective distress occasioned by the characters' disturbing situation, and the casting of visibly disabled actors in the roles of Hamm and Clov emphasises this unsettling dynamic for many spectators, to a discomfiting degree.

Robson and Shaban themselves acknowledge the potential role played by their impaired bodies in preventing any comfortable recognition or easy assimilation of the onstage situation. Robson notes that his appearance 'can help create a sense of otherness' for able-bodied spectators 'who sometimes still struggle with seeing a disabled body on stage' (Robson, 2017). Shaban, despite his rejection of Quayson's broader theorising of some invariable encounter with the disabled body, similarly testifies to the reality of an anxious or distressed response to what he terms his own 'uneasy body', both on and off the stage:

It is conceivable that a certain section of the audience on seeing me for the first time may feel a kind of panic - I don't know if it's a moral panic - and they may feel uneasy. And I'm pretty sure that on a day-to-day basis, if I encounter someone on the street and they see me for the first time, they may well feel uneasy, and wonder, 'Oh god, how do I react to this' or whatever. [...] And I think in theatre I don't delude myself that the first five minutes of my arrival on the stage, there could well be gasps from the audience, or shock, or 'Jesus Christ, what the fuck is that?' In fact, I have heard something like that being said when I'm seen by the audience for the first time and think, well, they've not seen disabled people or they've not been exposed, and you've got to expect it. (Shaban, 2017)

Shaban and Robson identify Endgame as a play that is not 'about' the material reality or lived experience of disability as such, but rather one which draws on the affective resonance of the performance of impairment on stage in order to generate a spectatorial disquiet. In this context, they recognise their own impaired bodies as ideally fitted to perform these roles. Shaban draws explicit attention to his own superiority as a performer of Endgame in this respect: 'I can't imagine a non-disabled audience going to see non-disabled actors who are pretending to have some kind of impairment, are going to feel any unease, because they know it is just a piece of 
theatre. They're not stupid' (Shaban, 2017). The rather circumspect ethics both of textual rescripting and of using the disabled body as a source of able-bodied anxiety are reshaped into a revealingly close attention to the aesthetic demands of Beckett's script - and this attention establishes the disabled performer as proffering an aesthetically exemplary body on stage.

\section{The Endgame Project, dir. Joe Grifasi, Classic Stage Company, 2012}

The Endgame Project, directed by Joe Grifasi and staged at the Classic Stage Company theatre in New York in July 2012, starred two actors with Parkinson's disease, Dan Moran and Chris Jones, playing Hamm and Clov respectively. Moran explains that the project began when he started reading a copy of Endgame during a bout of insomnia in 2011: 'I was in full-blown Parkinson's mode, and I thought, "This is exactly what fucking Parkinson's is like"” ('Dan's Story', 2012).

I just felt, like, this guy is, like, talking about my life here, about Parkinson's. That's what it really felt like. [...] I thought, Parkinson's. And I thought the room, they're locked in this room, and I thought, oh, Parkinson's. One guy can walk, one guy can't: Parkinson's. ('The Actors Discuss', 2012)

Jones and Moran have observed further specificities of the parallels between the symptoms of Parkinson's and the scripted details of Endgame. The sudden memory lapses and difficulty of 'com[ing] up with the simplest words sometimes' that often typify Parkinson's ('Dan's Story', 2012), for example, are reflected in the play's concern with diminishing memory and 'the words that remain' (Beckett, 2006, 132). Jones's experience of it getting 'harder and harder to move' his body, the loss of the ability to make his limbs move at will (Radiolab Live, 2013), is echoed in Hamm's warning to Clov about the inevitable demise of bodily function: 'One day you'll say to yourself, I'm tired, I'll sit down, and you'll go and sit down. [...] But you won't get up' (Beckett, 2006, 109). The chronic pain that operates as one of the non-motor symptoms of Parkinson's is paralleled in the 'unbelievable' pain in Clov's legs (115) and in the protracted physical suffering that drives Hamm's repeated requests for painkillers. Patrick Bixby draws attention to Beckett's first-hand knowledge of the symptomology of Parkinson's $(2018,119)$, highlighting Jones and Moran's particular aptitude for performing Hamm and Clov: 'Who 
could embody these figures more fully? [...] Who could better understand this hesitation to end, this desire to endure?' (113).

However, The Endgame Project did not claim to have identified any specific 'diagnosis' for Hamm and Clov, and Bixby likewise clarifies that he traces Beckett's direct experience of Parkinson's patients 'not to identify a particular referent for the images of disability in Endgame, but to suggest a certain urgency' in Beckett's writing about the deteriorating body on stage $(2018,121)$. Jones carefully specifies a relationship of resonance and parallelism between his illness and Beckett's play, rather than one of precise representation, pointing to 'a certain elegance to the thought that in our production of Endgame two actors with diminishing physical abilities would be playing two characters with diminishing physical abilities' (Jones, 2017). He rejects the idea that his experience of Parkinson's gives him any innate or corrective comprehension of Clov's character beyond the play's scripted detail, maintaining that 'the argument that we would be better able to understand the characters we were playing because of our Parkinson's is one that does not hold water' (Jones, 2017), and more circumspectly citing the theory of acting that 'the way an actor gives depth to a character is by having secrets that nobody else knows. And it is conceivable that the secrets for Hamm and Clov could be that they suffer from Parkinson's' (Jones, 2017). Parkinson's here becomes simultaneously a biological fact and a concealed hypothetical lurking in the margins of The Endgame Project, rooted in the onstage bodies of the performers but not necessarily in those of the characters themselves. The disabled actor's body again becomes a direct actualisation of the script's attention to a material mode of alternative embodiment, rather than a claim to any specific diagnosis applied to the text's characters.

This embodied actuality produced a striking impact in performance. Jones recalls, 'The response was fantastic. Audience members commented that the play had never been clearer' (Jones, 2017), suggesting that the tangible presence of Jones's and Moran's physical impairments on stage rendered more viscerally to spectators the script's probing of bodily vulnerability and threatened demise. In particular, the sheer precarity of Jones's and Moran's bodies on stage provoked an intensified affect of physical contingency, of constant nearcollapse or 'near-ending', well suited to Endgame's textual concerns. Alongside the unavoidable challenges occasioned by the production - such as learning a long and exacting script despite the memory impairment caused by Parkinson's and managing medication to fit with rehearsal schedules - Jones and Moran cast the roles of Hamm and Clov between them so as to deliberately exacerbate their own physical difficulty in performance. Moran explains: 
We decided, Chris is having more trouble with his movement than I am, and I'm having more trouble with my speech than Chris is, so I thought, well, why don't I take on the part with all the speech, and you got trouble with moving, so you do the part with all the movement - that makes sense. (Radiolab Live, 2013)

Jones cites this heightened physical difficulty as a critical resource in performance, explaining that 'the only thing our production would have over an able-bodied production is a certain tension derived from the fear that the whole thing was just going to implode' (Jones, 2017). By committing to the physical difficulties of performance, Jones and Moran generate another specific form of disability-related 'aesthetic nervousness', one occasioned by the radical contingency of their own bodies onstage. This is a high-risk strategy that simultaneously threatens and serves the performance at hand - or, rather, serves the performance precisely by threatening it. In emphasising the profound bodily vulnerability of its actors, who nevertheless continue with the performance at hand, The Endgame Project aligns its performance aesthetics with the unrelenting textual menace of some catastrophic or entropic 'end' to come, twinned with its characters' persistence in 'remaining' in play.

\section{Not I, dir. Matthew Pountney, Battersea Arts Centre, 2018}

Jess Thom's Touretteshero performance of Mouth in Not I provides another example of a disability performance that simultaneously seems to threaten and yet triumphantly upholds the aesthetics of Beckett's play. Thom has Tourette's Syndrome and exhibits both motor and verbal tics. For any performer, the role of Not I's Mouth is a difficult one, demanding that the actor deliver a complex text at high speed and with extreme precision, while being physically held in place so that their mouth remains spotlit on an otherwise dark stage. Thom has acknowledged the pressure of the undertaking, calling Not I a 'difficult second album' following the success of her raucous self-penned Backstage in Biscuitland 2014 show (Thom, 2017) - the title of which makes reference to her most common verbal tic, 'biscuit' - which was created partly in response to Thom's own difficulty in accessing the theatre auditorium as a spectator whose body would not necessarily remain quiet enough to satisfy strict notions of acceptable audience etiquette (Simpson, 2018, 227-9). Co-developed with long-term collaborator Matthew Pountney, her production of Not I first ran at the 2017 Edinburgh Fringe Festival, where it 
garnered glowing reviews. The production was revived at Battersea Arts Centre in 2018 and has since toured across the UK and the US.

The production's triumph can be in part explained by its success in employing the ethics of disability representation and access accommodation as the basis for a convincing new reading of Not I's scripted aesthetics. While the exacting precision of Not I's script might seem to render it a particularly difficult challenge for disability performance, there are marked parallels between the text's evocation of involuntary speech and movement and the symptom profile of Tourette's syndrome. Ulrika Maude has traced in detail Beckett's awareness of Tourette's syndrome and its likely influence on the representation of the automatic and the involuntary in his writing (Maude, 2008), but Thom goes still further and reads Mouth herself as a disabled figure: 'We're claiming Mouth as a neurodiverse character and understanding her experience from that perspective' (Thom, 2017). She explains, 'There's loads of stuff within that text that I relate to deeply, that resonate with me deeply from a 'lived experience' point of view', pointing out the similarity between her own experience of Tourette's and Mouth 'experiencing these extremes of language' and 'not recognising that voice as her own' (Thom, 2017). Multiple moments in the script offer evocations of involuntary and uncontrolled language that speak to the lived experience of verbal Tourette's tics: 'words were coming... a voice she did not recognise' but 'finally had to admit... could be none other... than her own...' (Beckett, 2006, 379). Thom points to 'whole body like gone' (381) as her favourite line in the text, citing it as an apt description of how her own body feels during a 'ticcing fit' (Thom, 2017). This lived experience of involuntary speech and movement fits Thom consummately to the task of performing Beckett's script. As Thom herself notes, 'I was really interested in the idea of whether I was at a neurological advantage with a text like Not I because I have such experience of automation anyway' (Thom, 2017).

To draw on the value of Thom as a performer with Tourette's on stage, however, means accepting the spontaneous incursion of her uncontrolled speech and movement into all moments of the performance. The involuntary, after all, cannot be scripted. As a result, the Touretteshero production of Not I was a compelling mix of the meticulous and the innovative. Thom emphasises that her performance was a 'rigorous presentation of the play, honouring that text and the stage directions' (Thom, 2017), but this textual rigour operated alongside the incursion of her spontaneous verbal and motor tics during the performance, and the reworking of the traditional close restriction of Mouth's performer to allow for Thom's physical tics. In fact, Thom's verbal tics often subsided in frequency during the performance of the fast-paced monologue, perhaps as a result of the script's relentless pacing, but were liable to burst out 
more strongly in the moments of scripted silence. For example, in the pause after each 'What? Who? No? She!', her primary tic 'biscuit' re-surfaced in a quick-fire burst that typically remained pleasingly consistent throughout each performance: a four-beat 'Biscuit-biscuitbiscuit-biscuit', each word accompanied by Thom's physical tic of a thump to her chest. As Derval Tubridy observes, Not I's textual evocation of the involuntary body was thus rendered material through Thom's own embodied being as a performer on the stage, 'creating for the audience a multi-layered experience of Beckett's script in which ideas integral to the play are enacted within the performance' (Tubridy, 2018). As a result of both its consciously controlled and consciously uncontrolled components, Thom's performance effected a double work upon the stage, as she both acted Mouth's scripted words and enacted her own experience of involuntary speech and movement.

Beyond the inclusion of Thom's verbal and motor tics, the Touretteshero production of Not I was distinguished by another innovation in staging: the reworking of the Auditor as a British Sign Language (BSL) translator, as performed by Charmaine Wombwell. While this adaptation operated most obviously as an audience access measure, the interplay between Thom's spoken monologue and Wombwell's signed accompaniment also generated a new version of the unsettling sense of disembodied fragmentation that pervades the text. In earlier productions of Not I, the concealment of the performer's body and the darkness of the auditorium has typically created the illusion of a disembodied, floating mouth, and the consequent sense of a disembodied form of speech fragmented from any cohesive bodily identity. Here, the Touretteshero production 'split' two versions of Mouth's monologue across the stage, separating a 'primarily verbal' language from a 'primarily bodily' language between its two performers, in a new stage rendition of post-Cartesian subjectivity. With Thom elevated in her wheelchair on an eight-foot-high platform on stage left and Wombwell standing at ground level on stage right, the spectator was forced to continuously choose between watching Thom or watching Wombwell's signing, fragmenting still further any sense of a definite or discrete 'speaking identity'. Just as the incorporation of Thom's motor and verbal tics into the performance offered both an inclusive access measure and a radical new realisation of Beckett's exploration of bodily agency, here too the reworking of the Auditor as a BSL interpreter became an integral part of the play's aesthetic functioning in close correspondence with some of the script's central concerns. The continuing critical success of Touretteshero's Not I underlines the triumph of Thom's production in terms of both Beckettian aesthetics and access ethics. As Leah Sidi observes, the Touretteshero production did not 'transform' Not I but rather 're-discovered it', re-training the spectator's eye onto new social and ontological 
implications 'even as it uses the same words the play has always used' (Sidi, 2018). Thom's Not I is not merely a permissible 'access version' of Beckett's play, but rather a revelatory exploration of the struggles associated with bodily autonomy and social inclusion, enacted at an embodied level in performance.

\section{Waiting for Godot, dir. Sam Curtis Lindsay and Daniel Vais, Hackney}

Showroom, 2018

In 2018, Hackney Showroom's artistic director Sam Curtis Lindsay and Culture Device's Daniel Vais co-directed Tommy Jessop (Vladimir), Otto Baxter (Estragon), Sam Barnard (Pozzo) and the aptly named Rishard Beckett (Lucky), a cast of professional actors with Down syndrome, in a series of rehearsals leading up to a single public performance of Waiting for Godot. Vais, who originated the idea of the production, says that the Beckett Estate has to date not answered any of their attempts at contact. 'Even if they say no, I want to do it anyway', he adds. 'So sue me. Put me in prison! It's politically important to do this. These men have been told 'no' over and over again in their lives: I'm not going to have them be told that they can't do this, either. I'm not going to be one more person saying 'no' to them' (Vais, 2018). ${ }^{3} \mathrm{He}$ wants, he says, to take the production to Ireland, to make Waiting for Godot a flagship for professional Down syndrome performance. He's fiercely proud of his actors, reeling off their considerable accomplishments: Baxter's last film project (Samuel-613, 2014) was shortlisted for the BAFTA Best British Short Film, and he won Best Actor for his role in Ups and Downs (2013) in the 2015 Cannes 'Festival Entr'd Marches' in 2014; Jessop was the first actor with Down syndrome to play Hamlet professionally (with Blue Apple Theatre in 2012) and to star in a prime-time BBC Drama (the BAFTA-nominated Coming Down the Mountain, 2007). 'People are scared to work with them', Vais says. 'They think they won't be able to fulfil the text's requirements. You have to work with them, or come to watch them, to really see their potential' (Vais, 2018).

The Hackney Showroom production placed a radical mixture of vulnerability and simultaneous endurance on stage, exemplifying how alternative embodiments can provide distinct advantages in Beckettian performance, how 'disability can be something beneficial', as Vais puts it. With its looping structure and minuscule alterations in near-repeated lines of dialogue, Waiting for Godot is an infamously difficult script to learn. A short-term memory 
deficit is one cognitive dysfunction sometimes associated with Down syndrome (Roberts and Richmond, 2018), and for their first public performance, the company offered a slightly abridged version of the play - although both Vais and Curtis Lindsay stressed that their precautionary measures turned out to be unnecessary: 'They learned the text fantastically', Vais recalls. As with Thom's involuntary speech in Not I, here too there was an aesthetic authenticity to be gained by coupling this alternative neurological functioning with a play so centrally concerned with compromised memory. The characters struggle to remember the Bible (Beckett, 2006, 13), to remember exactly where and when Godot told them to wait (16-17), to remember if they know Pozzo and Lucky from the past (47), to remember what they did yesterday (56-7). Jessop played a laconic and angrily pensive Vladimir, a character he describes as being 'philosophical' yet 'full of powerful emotions' (Jessop, 2020). He has an occasional stammer that pulls his lines into a protracted, drawling rhythm. His stutter caught on the word 'Godot' in the famous refrain: 'We're waiting for Godot.' 'We're waiting... for...' He waits, willing the word to come, and the spectator waits with him: '...Godot'. This newly performative rendering of an otherwise familiar line asked the audience to re-engage with the lived experience of waiting itself, and by itself merited the standing ovation that the play received in performance. The production offered an exercise in performative patience and an exposition of co-dependency and potentially fallible memory: issues which lie at the heart of Beckett's original script.

Co-director Sam Curtis Lindsay has emphasised the importance of a re-conceptualised framework to his production, reflecting 'I'm not really interested in directing a virtuoso Godot. That's out there, that's been done' (Curtis Lindsay, 2018). Nevertheless, he stresses that the primacy of Beckett's script is uppermost in his mind 'I don't want it to turn into "a show about people with Down syndrome" to prove a political point or to "say something" about people with Down syndrome. That's not what the play is', he insists, adding 'I don't want to do something that's seen as lesser. My intention is to do something of quality, not a community project' (Curtis Lindsay, 2018). The production was conceived to stand on its own aesthetic merits - because of, rather than despite, the casting of actors with Down syndrome - and both directors have testified to the challenge of overcoming audience assumptions. Vais complains:

Everybody comes with preconceptions. [...] Openly, they say, 'Oh, I'm coming sceptically'. How do they know what the artist is going to do? You've never seen a cast with Down syndrome doing Beckett. So how can you come with 
preconceptions? You've never seen it before! Come with an open mind, come with excitement, and then decide. (Vais, 2020)

Curtis Lindsay concurs:

People go, 'Oooh', you know, 'People with disabilities, how cute! How sweet! How important! And how special!' And I think also that all of us, whether we like to admit it or not, we all have preconceptions about people with disabilities. [...] And that's not cynical; I think that's just a truth that exists that we have to acknowledge. (Curtis Lindsay, 2020)

The actors themselves are particularly focused on the tramps' ill-treatment in the play, which strikes a personal chord with them. Barnard recalls how, after his appearance in The Oxford Murders in 2008, people complained online about the 'retard' in the film (Barnard, 2018). Jessop, whom Curtis Lindsay describes as possessed of 'a really fierce intellect' but also 'a very feeling actor', cites one of his favourite lines from the play as 'People are bloody ignorant apes', adding, 'Because that's actually true. I think I might have met people like that. Teasing, winding people up. Some people are ignorant' (Jessop, 2020). Again, it becomes difficult here to untangle the threads of the textual aesthetic and the extratextual ethics suggested by Beckett's play in disability performance. What are the tramps waiting for, I ask? 'Hope', says Jessop (Jessop, 2018).

\section{Conclusion}

Contemporary cultural performance is increasingly engaged in debates over disability representation in mainstream entertainment. However, each of the productions discussed here constitutes part of the drive to produce aesthetically attuned and intellectually generative disability performances, rather than as any one-dimensional form of access measure. Nicholas Johnson and Jonathan Heron have recently observed the experimental productions of Beckett's play 'can lead to divergences from text, yet also produce a specific - and sometimes enhanced - Beckettian embodiment' (2020, 13). Disability performances likewise often translate crucial corporeal, social, and ontological concerns that run through Beckett's original playtexts, in 
strikingly immediate and embodied terms. Ideas about agency, co-dependency, social isolation, alternative forms of embodiment, and post-Cartesian subjectivity are rendered newly conspicuous, enacted in strikingly material terms before the audience's gaze. In response to my query whether disability might be 'the last remaining taboo' in arts representation, Clov actor Garry Robson rightly counters that it is, in fact, 'the last avant-garde' (Robson, 2017).

\section{NOTES}

1. This article takes as a grounding principle the disability activist doctrine, 'Nothing about us without us!', which protests against the exclusion of disabled individuals' voices and insights in matters relating to disability policy and culture. It thus draws heavily on a series of recorded interviews with disabled practitioners conducted as part of this research. The author would like to thank the practitioners who have offered their time - sometimes in very considerable measure - to being interviewed.

2. See, for example, Davidson (2019), Levin (2018), and Mitchell and Snyder (2000).

3. At time of writing, Hackney Showroom have confirmed that they are not willing to continue work on Waiting for Godot without Estate permission.

\section{WORKS CITED}

Barnard, Sam (2018), Interview with Hannah Simpson (March).

Beckett, Samuel (2006), The Complete Dramatic Works, London: Faber and Faber.

Bixby, Patrick (2018), “"this... this... thing”: The Endgame Project, Corporeal Difference, and the Ethics of Witnessing', Journal of Beckett Studies, 27:1, pp. 112-27.

Brown, Mark (2007), 'Endgame: Another Side of Beckett', The Telegraph, 28 November, https://www.telegraph.co.uk/culture/theatre/3669567/Endgame-Another-side-of-

Beckett.html; accessed 1 June 2020.

Clapp, Susannah (2006), 'Clarity in his Master's Voice', The Guardian, 22 October, https://www.theguardian.com/stage/2006/oct/22/theatre.haroldpinter; accessed 1 June 2020.

Cowell, Alan (2006), 'Life, Meet Art: Pinter's Last Stand', The New York Times, 21 October, https://www.nytimes.com/2006/10/21/theater/21pint.html; accessed 1 June 2020. 
Curtis Lindsay, Sam (2018), Interview with Hannah Simpson (March).

'Dan's Story' (2012), The Endgame Project, http://www.theendgameproject.com/trailer/

Davidson, Michael (2019), Invalid Modernism: Disability and the Missing Body of the Aesthetic, Oxford: Oxford University Press.

Garland-Thompson, Rosemarie (1997), Extraordinary Bodies: Figuring Physical Disability in American Culture and Literature, New York: Columbia University Press.

Horvat, Ksenija (2016), 'Mindscapes Among Thistle: Producing Samuel Beckett's Plays in Scotland' in David Tucker and Trish McTighe (eds), Staging Beckett in Great Britain, London: Bloomsbury Methuen Drama, pp. 157-76.

Jessop, Tommy (2018), Interview with Hannah Simpson (March).

Jessop, Tommy (2020), Interview with Hannah Simpson (April).

Johnson, Nicholas E., and Jonathan Heron (2020), Experimental Beckett, Cambridge: Cambridge University Press.

Johnston, Kirsty (2016), Disability Theatre and Modern Drama: Recasting Modernism, London: Bloomsbury.

Jones, Chris (2017), Interview with Hannah Simpson (October).

Levin, Yael (2018), 'Univocity, Exhaustion and Failing Better: Reading Beckett with Disability Studies', Journal of Beckett Studies, 27:2, pp. 157-74.

Maude, Ulrika (2008), 'A Stirring Beyond Coming and Going: Beckett and Tourette's', Journal of Beckett Studies, 17:1-2, pp. 153-68.

Mitchell, David T., and Sharon L. Snyder (2000), Narrative Prosthesis: Disability and the Dependencies of Discourse, Ann Arbor: The University of Michigan Press.

Nightingale, Benedict (2006), 'Krapp's Last Tape', The Times, 17 October, https://www.thetimes.co.uk/article/krapps-last-tape-cd9x31wdf3d; accessed 1 June 2020.

Quayson, Ato (2007), Aesthetic Nervousness: Disability and the Crisis of Representation, New York: Columbia University Press.

Radiolab Live (2013), 'Apocalyptical: The Beginning of the End', WNYC Studios, 9 December, https://www.wnycstudios.org/podcasts/radiolab/episodes/apocalypticallive-paramount-seattle; accessed 1 June 2020.

Roberts, L., and J. L. Richmond (2018), 'Using learning flexibly and remembering after a delay: understanding cognitive dysfunction in adults with Down Syndrome', Journal of Intellectual Disability Research, 62:6, pp. 521-31.

Robson, Garry (2017), Interview with Hannah Simpson (November). 
Shaban, Nabil (2017), Interview with Hannah Simpson (October).

Sidi, Leah (2018), 'A Hand on the Arm: Gesture, Neurodiversity and Performance', The Polyphony, 19 September, https://thepolyphony.org/2018/09/19/a-hand-on-the-armgesture-neurodiversity-and-performance/; accessed 1 June 2020.

Simpson, Hannah (2018), 'Tics in the Theatre: The Quiet Audience, the Relaxed Performance, and the Neurodivergent Spectator', Theatre Topics, 28:3, pp. 227-38.

'The Actors Discuss' (2012), The Endgame Project, http://www.theendgameproject.com/trailer/; accessed 1 June 2020.

Thom, Jess (2017), Interview with Hannah Simpson (February).

Tubridy, Derval (2018), 'Incommensurable Corporealities? Touretteshero's Not I.', Contemporary Theatre Review, Interventions, 28:1, https://www.contemporarytheatrereview.org/2018/touretteshero-not-i/; accessed 1 June 2020.

Vais, Daniel (2018), Interview with Hannah Simpson (March).

Vais, Daniel (2020), Interview with Hannah Simpson (April). 